\title{
Enunciación
}

http://revistas.udistrital.edu.co/ojs/index.php/enunc

DOI: http://dx.doi.org/10.14483/udistrital.jour.enunc.2014.2.a11

enunciación

ARTÍCULO DE REVISIÓN

\section{Pedagogía alemana o la religiosidad estética de la guerra}

\section{German Pedagogy or Esthetic Religiousness of War}

\author{
Miguel Ángel Maldonado García ${ }^{1}$
}

Para citar este artículo: Maldonado, M. Á. (2014). Pedagogía alemana o la religiosidad estética de la guerra. Enunciación, 19(2), 305-317.

Recibido: 17-julio-2014 / Aprobado: 10-octubre-2014

A la Odisea debo una de las más deleitosas experiencias de mi vida, y en gran parte, mi amor a la educación

(Herbart, 1941, p.18)

\section{Resumen}

Se remueven ${ }^{2}$ tres sedimentos semánticos Bildung, Bildungsroman y Paideia. Mediante la historia de los conceptos (Begriffsgeschichte) de Koselleck se recuperan cuatro textos canónicos escritos en periodos bélicos en la construcción de la nación alemana, siglos XVIII y XX. Se observa cómo, desde una perspectiva estética y cultural, el método experimental entró en diálogo con una nueva religiosidad social, comprometió la pedagogía y logró convertirse en una utopía singular y colectiva alemana.

Palabras clave: Bildung, Bildungsroman, Paideia

\begin{abstract}
This article describes the removal of three semantic sediments; Bildung, Bildungsroman and Paideia. Through the history of concepts (Begriffsgeschichte) of Koselleck, four canonical texts are recovered, these were written in war periods in the construction of the German nation in the 18th and 20th centuries. It is noted how, from a cultural and aesthetic perspective, the experimental method entered into dialog with a new social religiousness, compromised the pedagogy and managed to turn in a collective and singular German utopia.
\end{abstract}

Keywords: Bildung, Bildungsroman, Paideia

1 Doctor en Educación. Docente asistente de la Maestría en Pedagogía de la lengua materna, Universidad Distrital Francisco José de Caldas. Correo electrónico: avancemosenpedagogia@gmail.com

2 Este artículo no pretende descifrar el desarrollo universal o evolutivo de la pedagogía en el que insisten muchos manuales, pues ni el discurso ni la práctica pedagógica son estables ni han estado siempre en el mismo lugar, tampoco se han expresado de la misma forma: van y vienen, cambian y se matizan, se solapan y se adecúan a los acontecimientos y a los juegos de poder construyendo de modo incesante diversas geografías y sujetos que a veces emergen en contextos inesperados. 


\section{INTRODUCCIÓN}

La agonía de la monarquía y la vulgarización de la Biblia, o su escritura en lenguas vernáculas, desembocó en la pérdida de confianza en el poder y en la sacralización del conocimiento. Se abrió un universo heliocéntrico e inmenso, la opción de leer otros textos en lenguas vivas y la insistencia de filósofos pedagogos en una autoconciencia social que remplaza una idea arraigada del orden, trazan una línea divisoria entre la Edad Media y la Modernidad: el concepto de Bildung emerge con la vulgarización de la escritura. Para Michel de Certeau (2000), Guglielmo Cavallo y Roger Chartier (1998), las prácticas de la escritura y de la lectura son el indicio de la Modernidad pedagogizante y la proclama de que la ciencia debe estar por escrito.

En este marco, Alemania construye el concepto de pedagogía sobre los residuos de Bildung, Bildungsroman y Paideia, los cuales constituyen el horizonte de sentido de un conglomerado humano ilustrado, resquebrajado y urgido de identidad, pero que se abre paso gracias a la lectura intensiva y extensiva en tres escenarios bélicos: la Revolución Industrial Inglesa, la Revolución Francesa y la Segunda Guerra Mundial. En este punto es necesario parafrasear dos afirmaciones de Koselleck: a) Bildung ${ }^{3}$ influyó en la política y en la economía alemana del siglo XIX y del siglo XX y b) Bildung es una palabra alemana, lo cual dificulta mucho encontrar equivalentes en español u otros idiomas (2012, p.52). Se apresuran quienes lo reducen a cultura, educación o instrucción.

3 "El concepto alemán de Bildung se caracteriza por refundir el sentido de una educación [Erziehung] procedente del exterior, todavía inherente al concepto en el siglo XVIII, en una pretensión de autonomía que consiste en apropiarse personalmente del mundo. En este sentido, Bildung se diferencia de forma fundamental de education. En segundo lugar, el concepto alemán de Bildung se caracteriza por no referir ya el ámbito de la comunicación social a la societas civilis concebida políticamente, sino a una sociedad que primordialmente se concibe mediante la diversidad de la Bildung que le es inherente. En este sentido, el concepto de Bildung se diferencia de civility y civilisation. Por último, el concepto alemán de Bildung se caracteriza por vincular las actividades culturales de la comunidad, a las que por supuesto también se refiere, a una reflexión personal interior sin la que no podría haber una cultura social" (Koselleck, 2102, p.53).

\section{METODOLOGÍA}

La historia de los conceptos es un método histórico para investigar los juegos del lenguaje en contextos sociopolíticos determinados (Koselleck, 1993, 1997, 2001, 2007 y 2012). Los corpus que permiten remover estos estratos semántico temporales son cuatro textos canónicos alemanes: Los años de aprendizaje de Wilhelm Meister (1797 y 1798), escrita por Wolfgfang von Goethe (1749-1832); el Tratado de pedagogía (1803) de Immanuel Kant (1724-1804); Pedagogía general. Derivada del fin de la educación (1805) de Johann Friedrich Herbart (1776-1841); y Paideia (1942) de Werner Jaeger (1888-1961). Dichos textos han sido ordenados bajo el supuesto de que la historia conceptual de Bildung se da en tres momentos: uno teológico, otro pedagógico ilustrado y uno moderno (Koselleck, 2012, p.57). Además, este artículo se adscribe a Koselleck en cuanto Bildung es un metaconcepto inestable "que constantemente incorpora en sí mismo las condiciones empíricas que lo hacen posible" (Koselleck, 2012, pp.63-64). Dicha inestablidad hace que se mantenga activo y se adhiera a otra suerte de conceptos que, al igual que el de pedagogía, sea capaz de regresar y avanzar en periodos de corta y larga duración, sin que el ususario del mismo lo perciba o sea consciente de esta práctica.

Con los cuatro textos señalados se construye un campo semántico que permite ver cómo se tensionan los discursos en torno al concepto de pedagogía. Le compete a este artículo la deconstrucción del concepto en ciernes en tanto sedimentación de índices o señales que se constituyen en evidencias de las tensiones y transformaciones históricas en la formación de la conciencia y en el control de los comportamientos sociales. Los textos objeto de trabajo son vistos como artefactos culturales o productos de un contexto socio histórico determinado. Son interpelados no como documentos sagrados e incuestionables sino como productos que muestran distintas representaciones conceptuales en distintos estratos semántico temporales de larga y corta duración, según Koselleck. 


\section{Pretextos}

La producción sobre los conceptos en ciernes es densa, razón por la cual este artículo solo dialoga con textos contemporáneos traducidos al español por investigadores como Lorenzo Luzuriaga (1946), Frederick Mayer (1967), Michel de Certeau (2000), Cavallo y Chartier (1998), Conrad Vilonou (2002), Miguel de la Torre Gamboa (2009), Víctor Escudero Prieto (2010), Michel Fabre (2011), Joaquín Abellán (2003) y Reinhard Koselleck (2012). ${ }^{4}$ Además, con trabajos de algunos investigadores colombianos como Alberto Montealegre ([1957], 2007), Olga Lucía Zuluaga (2003), Humberto Quiceno (2003), Andrés Klaus Runge (2009), Ernesto Noguera (2010), Runge y Garcés (2011) o Alberto Martínez Boom (2011), quienes se han ocupado del discurso pedagógico alemán.

\section{Wilhelm von Humboldt: el discurso educativo de la modernidad}

Humboldt (1767-1835) en Los límites de la acción del Estado (1792), comprende la Bildung como cultura o conjunto de imágenes y representaciones de una persona y de una comunidad en su proceso de autoconstrucción. A Humboldt le correspondió la tarea de pensar la creación del Estado alemán, ${ }^{5}$ luego de la guerra prusiana con el ejército napoleónico (Jena, 1806) que dejó al país devastado. Observó que los actos pedagogizantes dependen de la experiencia de los profesores; así, la Bildung escenifica la formación más como experiencia que como didáctica escolar, el sujeto se

4 Se destaca entre estos la investigación que se publicó recientemente como Sobre la estructura antropológica y semántica de Bildung, dada su magnitud, profundidad y, especialmente, por ser historiador de los conceptos.

5 Luzuriaga relata que entre 1807 y 1817, luego de la derrota de Prusia a manos de Napoleón, se despertó un sentimiento nacional sobre las ruinas del Estado. Intelectuales como Stein, Fichte y Humboldt reconstruyen "el edificio público derruido", dotándolo de bases más firmes que las anteriores. Transforman el Estado autoritario napoleónico construido por súbditos en un Estado Nacional conformado por ciudadanos sobre la base de una educación fuerte y el método pestalozziano (Luzuriaga, 1946, p.121). Ver Confederación Germánica o Constitución del 8 de junio de 1815. forma en el desamparo de la vida. Profundizó sobre el sentido científico y humanista de la Bildung y le da el sentido de formación, se le valora su labor filosófica, lingüística y de gestión; sistematizó su producción discursiva en la fundación de la Universidad de Berlín (1810). En su labor puso en práctica un concepto de humanismo, investigación, moral, estética y pedagogía que discrepa del absolutismo racionalista e ilustrado que, para él Humboldt, minimizó lo estético y moral.

Joaquín Abellán ${ }^{6}$ señala que para Humboldt el concepto de nación es sinónimo de Bildung y expresa la dimensión humana del proceso de formativo, moral e intelectual: Bildung tiene un contenido más elevado e íntimo que el que de cultura o el de civilización (Abellán, 2003, p.344). Así las cosas, la conexión entre nación y Bildung desemboca en el desarrollo de un sujeto que no discrepa del gobierno monárquico ni piensa la nación como una entidad propia y absoluta que sacrificaría la individualidad y libertad del sujeto.

Para Michel Fabre, la palabra Bildung tiene tres acepciones: "imagen (Bild), modelo (Vorbild), imitación (Nachbild)", que sintetizan y superan los significados "de form (forma), de Kultur (cultura) y de Aufklärung (Ilustración)". Para él, la Bildung emerge del misticismo medieval, cuando "el hombre lleva en su alma la imagen (bild) de Dios, a partir de la cual ha sido creado y la cual debe desarrollar". Serán Herder y Humboldt quienes se comprometen con el significado de Kultur a Bildung (Fabre, 2011, p.215). Por su parte, el historiador conceptual Conrad Vilonou, resume el significado de Bildung en un idealismo que devela su origen místico y que se desmarca de la Ilustración: "La Bildung se elevará entonces por encima de la Kultur, comprendida como simple educación de los talentos o de las facultades" (2002, p.218).

Se observa que los acontecimientos acaecidos en Europa entre los siglos XVII y XIX sitúan este periodo como el inicio de una modernidad

6 Joaquín Abellán es quizás el traductor hispánico más acucioso de la obra de Humboldt. 
alemana que funda su propia nación, coloniza y traza límites territoriales, de esta forma, da cabida a un renacimiento humanista que remueve los sedimentos grecorromanos de los cuales emerge el concepto de pedagogía depositario del enunciado de Bildung. Asimismo, en el marco de los burgos, la industrialización y los desarrollos tecnológicos, se dispone una forma inédita de capital con implicaciones en los procesos educativos, en la forma de hacer la guerra y de pensar la construcción de nación. Aparecen entonces instituciones de formación como las congregaciones religiosas, las academias militares y los centros tecnológicos en donde reinan la filosofía, las matemáticas, el cálculo y la contabilidad: en las primeras, se formarán los nobles; en las segundas, los hijos de los comerciantes y en las últimas, los obreros. En este periodo, la lectura es más extensa y también más intensa, al decir de Roger Chartier (1998).

Abellán concluye que para Humboldt el concepto de "nación" enfatiza en la dimensión humana del proceso formativo y en el "perfeccionamiento moral e intelectual, que es lo que está encerrado en el término alemán Bildung" y hace dos advertencias: a) Humboldt da a Bildung un contenido más elevado e íntimo que el que le da a la "cultura" y a la "civilización " (Kultur y Zivilisation)"; y "b) Esta íntima conexión entre nación y Bildung remite esencialmente al desarrollo del hombre individual, de modo que la nación no puede entenderse como una entidad propia, hipostasiada, por encima de los individuos (p.344).

\section{Bildungsroman: prácticas pedagógicas de lectura y escritura}

La Bildungsroman ${ }^{7}$ o novela de formación, variante de Bildung, convoca una parte de la literatura canónica de los siglos XVIII y XIX que promueve

7 De este género se ocupó Bajtin ([1979], 1999) y, de modo reciente y en tono pedagógico, investigadores como Reinhard Wittmann (1998), Antonio Hernández (2004), Víctor Escudero Prieto (2010) y Carlos Rojas (2010). la valoración estética del sujeto con enunciados como desarrollo, maduración o evolución de un sujeto que se construye desde su infancia hasta su maduración, gracias a un ejercicio dedicado y progresivo y que en ocasiones tienen la tutela de un maestro.

Rousseau funda con Emilio (1762) la novela formativa moralista y reclama que los iletrados no solo escuchen la palabra sino que la lean y la escriban; para él, la escritura, no es distinta a instrumentos de trabajo como la agricultura: "El sujeto de la escritura es el amo; el trabajador en posesión de una herramienta que no es el lenguaje, será Viernes" (Certeau, 2000, p.152). Alemania entiende este proceso y dispone su infraestructura escrituraria.

Señala Reinhard Wittmann que Europa Central y Occidental fueron presa de la revolución cultural o revolución de la lectura, al régimen alemán no lo golpean los jacobinos, sino los lectores; folletos, pasquines, periódicos, revistas, pero de modo especial novelas moralizantes y textos útiles, la misma pasión que despertó Rousseau en Francia la propició Goethe en Alemania:

En ningún otro lugar [...] alcanzó de hecho unas dimensiones y una dinámica tan radical en lo social como en Europa central, donde estalló una enfermedad desconocida hasta entonces, extendiéndose a un ritmo trepidante; primera infección localizada, "la manía lectora" no tardó en convertirse en una "epidemia lectora" colectiva. (Wittmann, 1998, pp.437-438)

Werther produjo nuevas prácticas sociales como la lectura en grupo y la lectura solitaria: "La lectura autoritaria declamada, "frontal", del padre de familia, el clérigo o el maestro, irrumpe ahora una forma de reunión legitimada y formalizada mediante la lectura" (Wittmann, 1998, p.454).

La Bildungsroman es el relato romántico y pedagógico de la Bildung puesto en un racionalismo e idealismo estético que traza la hoja de ruta de la pedagogía alemana como una ciencia del espíritu en un escenario de religiosidad secular. La 
construcción discursiva de la ciencia experimental se da en paralelo con el romanticismo, con la novela formativa y con la recreación de la fábula, textos en los cuales el hombre asciende sobre la naturaleza, la usa, la manipula y la controla para lograr sus fines.

El investigador español Escudero procesa el concepto de Bildung desde la Bildungsroman y subraya los episodios y pasajes que impulsan la construcción de su conciencia y de su identidad. Toma como ejemplo, entre otros, a Wilhelm Meister, pues esta novela articula al sujeto cotidiano con Kant y, en general, con el idealismo (Escudero, 2010, p.2).

El discurso de Bildung cristaliza como experiencia en la novela, especialmente en Los años de aprendizaje de Wilhelm Meister (1796), considerada la novela alemana moderna de formación, artífice del idealismo estético alemán. ${ }^{8}$ Wilheim es un héroe que condensa las tensiones de los intelectuales: rechaza el absolutismo estatal provisto por la Revolución francesa y considera que la mera formación estética faculta al sujeto para propiciar su propia revolución espiritual, sin renunciar a Dios ni entregarse a la anarquía.

La apertura de fábricas, hospitales, clínicas, escuelas y centros de investigación a la par de teatros y salas musicales ocurre en este contexto donde no solo se pretende formalizar al sujeto sino además convertirlo en un sujeto "útil", en normalizarlo, en evaluarlo y en gobernarlo.

[...] al saludar Wilhelm a su madre, esta le reveló que el padre estaba muy disgustado y que en breve iba prohibirle sus visitas diarias al teatro.

-Aunque yo misma voy a veces al teatro - continuó- ahora debo maldecirlo, pues tu desmedido apasionamiento por esta afición

8 Goethe habrá de concluir su saga literaria con Fausto (1832), editada en los últimos años de su vida con distintas versiones conocidas en principio en doas partes en las que apela a la estructura de tragedia griega. perturba la tranquilidad de mi hogar. Tu padre me repite siempre: ¿Qué utilidad tiene? y ¿Cómo se puede perder así el tiempo?

- Ya he tenido que oírselo decir —repuso Wilhelm-, y tal vez le he haya contestado con vehemencia; pero, por el amor de Dios, madre, ¿es, inútil todo aquello que no llena la bolsa de dinero, todo aquello que no nos procura una posesión inmediata? (Goethe, 2008, pp.89-90)

Wilhelm se resiste a pensar o a vivir según lo establecido, quiere ser actor y lector de las obras de Shakespeare en las cuales encuentra el refugio a una sociedad que da muestras de un capitalismo subyugante y vulgar. Wilhelm quiere una revolución estética y se refugia en la lectura y la actuación.

Hay en los textos alemanes señalados un ordenamiento de lo que muchos pastores de la iglesia habían escrito en los catecismos como prácticas discursivas que orientaban la gleba y que son un referente importante o un enunciado al ritual de la moderna pedagogía que a veces se vuelve catecismo. Dominique Julia señala que desde el siglo XVII la iglesia tenía la preocupación porque la catequesis lograra verdaderos seguidores y creyentes, razón por la cual quisieron que los catequistas se esforzaran más por el desarrollo del sentido por encima del aprendizaje memorístico (Julia, 1998, p.408).

En las prácticas de catequesis se da una verdadera apertura a la formación de los cuerpos y las almas de la feligresía que con cánticos, alabanzas y señales desarrollaron una didáctica ilustrada que ingresará a la escuela con la enseñanza de los saberes útiles.

\section{Del Despotismo Ilustrado y la pedagogía alemana}

Para Koselleck, el siglo XVIII es de la Ilustración y el siglo XIX el siglo de la Bildung (Koselleck, 2012, p.58). Tanto el Despotismo Ilustrado (educación para el pueblo pero sin el pueblo) como 
Enciclopedismo reflejan el imperativo categórico social de la lectura y la escritura que se instaura en Europa como el fundamento del mundo pedagógico, literario, productivo e investigativo. Sobre estas premisas iniciarán las reformas educativas en la antesala de la Revolución francesa, deudora de la Revolución de la lectura; sin embargo la Bildung considera que el Estado absolutista es sinónimo del maquinismo y contrario a los fines humanos, este debe responder solo de la seguridad del sujeto. En este marco de tensiones discursivas la educación trata de ocupar el lugar religioso con nuevos discursos éticos, estéticos y morales.

El discurso francés, alemán e inglés se entremezcla, se tensiona pero se disemina: los galos enuncian y denuncian, los ingleses industrializan y los germanos reflexionan, sistematizan y ejecutan. La deconstrucción del discurso kantiano invita a ver cómo los epistemes racionales y la demostración corroen la fe y la tranquilidad depositada en una religión que pierde la hegemonía interpretativa sobre lo natural y lo humano. El método es una de las grandes preocupaciones de filósofos e investigadores del periodo de emergencia de la Bildung pues se asocia con modelos matemáticos de representación (Zuluaga, 2003). Hay que razonar rigurosamente, como en una proposición geométrica y asegurarse en todo momento que no se ha omitido ningún paso lógico.

René Descartes (1596-1650) sobre la lógica aristotélica, había refundado el método hipotético deductivo, el cual exige que una afirmación, en tanto científica o racional, obligue un axioma fundado en principios sustentables. Para Kant, Descartes ${ }^{9}$ es el primer hombre moderno, enuncia sus cuatro reglas derivadas de la geometría, ciencia que le permite organizar el mundo de modo racional.

9 Descartes construyó un camino de la razón sobre las siguientes premisas: No aceptar como verdadero aquello que no pueda ser comprobado de forma clara y precisa que es verdad. Es preciso dividir las dificultades de lo que se analiza en tantas partes como sea posible (método analítico). Se debe dirigir el pensamiento de acuerdo con un orden lógico y razonar rigurosamente, como en una proposición geométrica y asegurarse en todo momento que no se ha omitido ningún paso lógico.
Como concepto fundamental de la modernidad Bildung es simultáneamente el resultado de la Ilustración al tiempo que una respuesta a esta. Inicialmente, la Ilustración se concibió, desde la perspectiva de la historia de la filosofía, como un periodo a clasificar diacrónicamente con un programa que, sin embargo, pretendía ser atemporal y científico. La Ilustración va más allá de su determinación epocal, es permanente y repetible. (Koselleck, p.58)

Los principios cartesianos son leídos por los textos pedagógicos de Kant y Herbart como los procesos de análisis y síntesis de la modernidad. La producción discursiva de Kant, quien recupera a Rousseau, lo sitúa como un artífice de la modernidad epistémico pedagógica pues recrea la Paideia griega, da el giro copernicano sobre el proyecto racionalista de Descartes y la física de Newton en dos momentos en los que resuenan sus dos preguntas escritas en dos textos fundamentales: ¿Qué puedo conocer? o Discurso sobre la metafísica y ¿Qué debo hacer? o Crítica a la Razón práctica.

Kant cuestiona el talante científico de la metafísica con su consigna "atrévete a saber" para transitar por tres caminos: el mundo o la cosmología, el alma o la psicología y Dios o la Teología. Sus reflexiones alcanzan la denominada revolución del conocimiento: el sujeto construye los objetos, las categorías de espacio y tiempo son construcciones del sujeto. Los fenómenos emergen de una impresión sensible que se da a través de las percepciones del espacio y del tiempo.

Según el filósofo español Antonio Hernández (2004), Kant reconoce la imposibilidad de probar la existencia de Dios a través de la ciencia, sin embargo este ejercicio constituye en un pretexto regio para sus reflexiones sobre la sensibilidad y el entendimiento como los mecanismos que construyen los conceptos; el primero es pasivo pero permite captar las impresiones del mundo exterior sin que pueda afectarlo; el segundo es activo y suministra los conceptos al margen de la experiencia. Kant observa que algunos conceptos no se derivan 
de la experiencia pero si se aplican en la experiencia a la vez que hay conceptos teológicos que se escapan de la experiencia pero que no se llega a ellos por la vía de la razón.

Al finalizar sus días, Kant reflexiona sobre lo que habrá de ser su Tratado de pedagogía ([1803], $2004)^{10}$ con el cual anuncia a Descartes y vislumbra cierta psicología al servicio de la pedagogía:

El hombre es la única criatura que ha de ser educada. Entendiendo por educación los cuidados (sustento, manutención), la disciplina y la instrucción, juntamente con la educación. [...] Únicamente por la educación el hombre puede llegar a ser hombre. No es, sino lo que la educación le hace ser. Se ha de observar que el hombre no es educado más que por hombres, que igualmente están educados. [...] La educación es un arte, cuya práctica ha de ser perfeccionada por muchas generaciones. [...] porque las disposiciones naturales del hombre no se desarrollan por sí mismas. [...] Es de la mayor importancia que los niños aprendan a trabajar. El hombre es el único animal que necesita trabajar. (Kant, 2003)

Sin embargo, difiere del Despotismo Ilustrado en cuanto la intervención del Estado en la formación, $y$, al igual que Humboldt y Goethe, considera que este es un medio pues el fin es el hombre mismo. Describe tres Facultades del conocimiento humano: la sensibilidad, el entendimiento y la razón. El primero está demarcado por el espacio y el tiempo; la geometría permite la comprensión del espacio y las matemáticas del tiempo; el segundo permite reconocer los objetos; en tanto que la razón busca los juicios generales. Estas Facultades son la fuente del acto pedagógico que sintetiza en tres aspectos:

10 La edición de este texto se debe especialmente a la recopilación de varios años de trabajo docente que hiciera su discípulo T. Rink bajo el título Über Pädagogik (Bisquerra, 1996, p.19). El texto en referencia ofrece una introducción y análisis de Germán Vargas, quien motiva a los educadores para que recuperen esta disertación kantiana o antropología filosófica o antropología pedagógica. el cuidado del cuerpo, la instrucción o disciplina y la formación.

No obstante, para Koselleck, la Ilustración alemana conservó el sello teológico, lo que explica la filiación de los jóvenes hegelianos.

La esperanza de redención y la reivindicación de la educación convergen desde entonces en Bildung. En el siglo XVIII aparece la variante semántica que aproxima Bildung e Ilustración. Es la reivindicación de la educación de los que se ven a sí mismos como ilustrados la que sitúa el concepto de Bildung en el ámbito pedagógico. (p.57)

Kant y Herbart enunciaron el discurso de las Ciencias de la educación y la Pedagogía. La antropología filosófica o antropología de la pedagogía kantiana será determinante para la interpretación y desarrollo de la pedagogía moderna. Para Kant, los seres humanos son los únicos en potencia de ser formados, más que educados, esta potencia otorga la opción de convertirse en hombres: un formador ha de ser en primera instancia un buen hombre, con toda la carga semántica que el filósofo alemán le otorga a este concepto. Bajo estos argumentos se observa la esencia de la antropología pedagógica en cuanto contempla al hombre como ser en condición de formación en el marco social alemán ad portas de un capitalismo diseñador de formas y saberes que facilitan y regulan el control social. El filósofo de Koningsberg inaugura así una episteme pedagógica de la modernidad: las impresiones se producen por la sensibilidad; la relación entre la sensibilidad y el entendimiento es necesaria: la sensibilidad permite percibir los datos, el entendimiento permite comprenderlos. Anuncia así los denominados tres aprenderes; saber ser (emoción), saber hacer (motricidad) y saber saber (cognición).

\section{Pedagogía, ciencia de la educación}

Kant instaura la educación como una teoría y advierte la necesidad de crear la pedagogía como la 
ciencia de la educación, enunciado que ha ser recobrado por Johann Friedrich Herbart: ${ }^{11}$ si una experiencia educativa logra pasar de la empiria del acierto y el error hasta convertirse en un método de enseñar, entonces está cerca de la ciencia o de constituirse en pedagogía científica. Herbart busca con la pedagogía el ideal de la perfección, esta debe "asegurar el desarrollo libre y placentero a todas las manifestaciones del crecimiento en el hombre desde la cuna al lecho nupcial". Concluye que: "Vivir es el oficio que enseña" (Herbart, 1941, p.2).

Si los que quieren edificar [...] la educación sobre la experiencia dirigieran una mirada atenta a las otras ciencias experimentales, si se dignaran informarse de todo lo que hay que hacer en física y en química para establecer el campo de la experiencia [...] experimentarían que no se aprende nada con una experiencia, y mucho menos con observaciones dispersas; que es preciso repetir veinte veces, de veinte maneras distintas, el mismo ensayo, antes de obtener un resultado que las teorías más opuestas explican después a su modo. Experimentarían que no se puede hablar de la experiencia hasta que no se ha terminado el ensayo [...] El aposteriori de los experimentos pedagógicos son las faltas que comete el alumno en la edad viril. Así, la duración de uno solo de estos experimentos es por lo menos igual a la mitad de la existencia humana ¿Cuándo, es pues, es un educador experimentado? (Herbart, 1941, p.6)

El método experimental herbartiano o positivo ocupó los siglos XIX y XX y mostró un nuevo campo en las disciplinas del hombre: con Herbart, la apropiación del método experimental incuba los discursos de las ciencias sociales.

Herbart trabajó en la Universidad de Königsberg, dando continuidad al Seminario Pedagógico iniciado por Kant, abrió una escuela en donde adelantó

11 El profesor Runge Peña (2009) afirma, con razón, que aunque bastante mencionado, Herbart es un autor desconocido y poco estudiado en el ámbito nacional. exploraciones sobre la relación entre piscología y pedagogía que lo señalan como precursor de la pedagogía científica. La faena discursiva de Herbart siembra semillas en la modernidad pedagógica y psicológica en tono científico; propuso un nuevo orden en la filosofía rousseauniana, la psicología, la sociología y la medicina o fisiología que, junto con la biología y la física, serán las ciencias del sujeto y de la sociedad. Sus hallazgos serán el dispositivo de observación de una pedagogía emergente que observa las aulas como si estas fueran laboratorios en donde se disecciona y se medica el cuerpo del niño como sujeto de enseñanza y aprendizaje y como objeto de formación moral y eugenésica.

Aunque diversos autores habían producido textos didácticos, el mérito de Herbart es que reflexiona durante más de veinte años sobre los conceptos de ciencia y moral y sobre pedagogía y didáctica, así lo muestra en sus textos Pedagogía general (1806), diez años más tarde (1816) amplía su horizonte en su Manual de psicología y luego con La psicología como ciencia nuevamente fundada en la experiencia, la metafísica y la matemática (1824) con los cuales establece el valor científico de estas disciplinas emergentes en el marco de la educación decimonónica. Herbart ${ }^{12}$ sitúa en el mismo campo la psicología o la ciencia y la estética al servicio de la voluntad y la moral como fin último de la

12 Herbart, no menos que Locke, Berkeley o Hume y otros investigadores de los siglos XIX y XX dan cabida al método experimental en la pedagogía y en la medicina: Claude Bernard (1801-1887), Robert von Mayer (1814-1878), Gustav Fechner (1801-1887), Wilhelm Wundt (1832-1920) y Johannes von MüIler (1801-1858), especialmente, son quienes aplican discursos y prácticas en "fenómenos psicofísicos y psicofisiológicos"; este grupo recoge principios filosóficos positivistas con prácticas de la física y la biología en la comprensión del sujeto en una especie de renacimiento decimonónico que se adentra en el cuerpo. El alemán von Mayer, quien además fuera físico, introduce en 1842 el concepto de conservación de la energía en los sistemas biológicos y físicos, eventos que le dan confianza a la psicología para verse como ciencia; se destaca de modo especial Wundt con sus Principios de psicología fisiológica. Con Auguste Comte (17981853) y Emile Durkheim (1858-1917) se produce un fenómeno similar al introducir discursos experimentales en las emergentes ciencias sociales. Montealegre cita a Paul Bert para referirse al trabajo médico investigativo de Bernard: "Por primera vez se habían trazado, y con mano maestra, las reglas del método experimental aplicadas a las investigaciones ejecutadas sobre los seres vivientes" (Montealegre, 2007, p.314). 
formación; reconoce la importancia de la experiencia por encima del espíritu que asocia las ideas a partir de la práctica en una suerte de dialéctica que tensiona el consciente y el preconsciente como puerta de entrada de la conciencia. Deposita toda su confianza en instrucción de un docente profesional o artista capaz de formar al infante o al adolescente al que considera como un ser carente o desprovisto de saberes y experiencias.

Considera que las ciencias empíricas deben trabajar desde sí mismas, es decir, desde sus propias prácticas sin que ciencias como la filosofía las gobiernen:

La primera ciencia del educador, anque no la única, habría de ser una psicología en la cual se determine a priori todas las posibilidades de las emociones humanas [...] el individuo se encuentra, no se deduce. La construcción del alumno a priori es, pues, en sí una expresión falsa y [...] un concepto vacio que la pedagogía no puede admitir por más tiempo [...] La pedagogía es la ciencia que necesita el educador para sí mismo. Pero también debe tener la ciencia para comunicarla [...] yo no puedo concebir la educación sin la instrucción e, inversamente, no reconozco [...] instrucción alguna que no eduque. (Herbart, 1941, pp.9-11)

Los hallazgos de la física y las matemáticas se instalan en la psicología y en la medicina en enunciados científicos de corte naturalista que son la plataforma sobre la cual algunos investigadores sociales del siglo XX abordan las problemáticas del sujeto social que pretende que todas las acciones humanas sean "útiles".

Runge Peña concluye que Herbart da continuidad a Kant en cuanto:

1) las pretensiones de sistematicidad de la pedagogía; 2) el cuestionamiento a la misma pedagogía como arte mecánico de la educación, ya que esta debe estar fundamentada científicamente y en principios; 3) la necesidad de la educación para superar el estado natural del ser humano, y 4) la moralidad como el fin más elevado del hombre. (Runge, 2009, p.69)

En el retorno a la Paideia Lorenzo Luzuriaga (1946) señala que al finalizar el siglo XIX, la educación pública alemana era ejemplo para Europa por su eficiencia técnica y administrativa. Era el país con menor número de analfabetos y con el nivel más alto en la enseñanza básica, secundaria y superior. "Pero, de igual manera, era un campo de tensiones entre reaccionarios y progresistas. Así también, la iglesia tuvo en ella una mayor intervención que en otras partes, conservando el carácter estrictamente confesional de su enseñanza" (Luzuriaga, 1946, p.134).

Recuerda Luzuriaga que durante el periodo nacionalsocialista se propusieron objetivos tales como: a) la formación del hombre como soldado político y subordinado, la creación de una conciencia racial nacional como entidad suprema; b) el desarrollo de la disciplina y la obediencia ciega a las autoridades políticas, el cultivo y endurecimiento del cuerpo en una forma parecida al ejercicio militar; y c) la subordinación de la educación intelectual a la política; la subordinación de la educación religiosa y política al Nacional Socialismo. Implicaría esto una negación o una desfiguración de sentido de Bildung o, al menos, una deshumanización de la misma.

Bajo este marco y en el fragor de la Segunda Guerra Mundial, el filólogo Jaeger, autor de Paideia, retorna a la educación ateniense de los siglos VI al IV (a.C.). Analiza la educación sobre la base de la estructura social con el propósito de cumplir una función humanista y política en un acto de fe:

Ya no existe el mundo que pretendía ayudar a reconstruir. Pero la acrópolis del espíritu griego se alza como un símbolo de fe sobre el valle de muerte y destrucción que por segunda vez en la misma generación atraviesa la humanidad doliente. (Jaeger, 1992, p.x)

Al igual que Rousseau, Goethe y Humboldt, Jaeger regresa a Platón para pensar la pedagogía de la 
modernidad en un escenario bélico de heroísmo y pretensiones de buen gobierno. Paideia relata la historia de la cultura griega a partir de su producción oral y escrita, busca los residuos de un hombre heroico que paulatinamente forjó ese grupo humano en un proceso de larga duración denominado Paideia.

Jaeger removió los sedimentos pedagógicos de la Grecia de Platón para pensar la modernidad alemana; considera que la educación, más que la pedagogía, no es posible sin que se ofrezca al espíritu una imagen del hombre tal y como debe ser. El hombre solo puede propagar y conservar su existencia social y espiritual mediante dos fuerzas vitales situadas en un cuerpo atlético: la voluntad consciente y la razón. Para José Lasso de La Vega, la generación de Jaeger tuvo la responsabilidad de combatir por la recuperación del humanismo clásico y de revisar la ciencia pedagógica desde la antigüedad griega: "Por la vía ética, política y pedagógica, en estrecha conexión con el problema del Humanismo, abre Jaeger la principal ventana para la comprensión del fenómeno griego, guardando estrecha fidelidad a la más genuina concepción griega del Humanismo" (Lasso, 1962, p.41).

En Paidea se dan cita los formadores de la Grecia primitiva. Homero, que sin ser educador de oficio logra en la práctica los mejores aprendizajes mediante su escritura. Sócrates y Platón se encuentran para recordarle a la humanidad que la ética, la moral y la estética, la filosofía y la epopeya son los mejores medios de comunicación entre los dioses y los mortales: estas son las mediaciones para forjar la educación del hombre. Jaeger quiso escribir un trabajo filológico literario sobre Platón pero produjo el mayor relato sobre la filosofía pedagógica griega.

Las sociedades poseen un modelo de educación que les permite conservar, transmitir y propagar su concepción de hombre, en tanto exista una acción consciente con unos fines establecidos. Jaeger comprende que para los griegos la poesía aventaja sin atenuantes la enseñanza intelectual y la verdad racional, esta expresión humana logra la mejor síntesis de la realidad espiritual y la hace más vital que el conocimiento filosófico. Si la intención es saber el cómo y el porqué de la pedagogía, es preciso releer la Iliada. Jaeger, a propósito de este relato, señala: "De ella nos viene la estrategia, la comedia, el trabajo filosófico, el diálogo, el tratado científico sistemático, la historia crítica, la biografía, la oratoria jurídica y encomiástica, la descripción de viajes, las memorias, las colecciones de cartas, las confesiones y los ensayos" (1992, p.31).

En la Ilíada, al igual que en la Odisea, se observa una utopía que ofrece las condiciones de posibilidad para que los nobles y el pueblo puedan trabajar por los mismos ideales altruistas provistos de una lógica y de una estética indisoluble en pos de un proyecto imperial. Paideia es el testimonio de que la savia de la pasión, de las utopías y del coraje puede estar inscritos en la formación de los hombres. Esta metáfora hace que los aprendices de guerreros y gobernantes, además de buenos oradores, sepan recitar tanto la Iliada como la Odisea: en Sócrates, Platón y Homero estriba la fuerza y el significado general del pueblo griego y estaría el ideal del pueblo alemán: la armonía del cuerpo, la disposición del lenguaje, el goce estético, la virtud o templanza y la capacidad oratoria.

De la Torre interpreta la Paideia, como Ideología de la Polis, o, lo que es igual

Como un modo de la actividad educativa cuya finalidad es que el individuo se vuelva virtuoso, alcance la arete e incorpore una dimensión ética a sus relaciones con los demás, en ese proyecto es clara la identificación entre política y educación: Politeia era el contenido de la vida de la polis, el saber con-vivir; Paideia, será el modo de acceder a ese contenido. (De la Torre, 2009, p.2)

\section{DISCUSIÓN}

El profesor mexicano Miguel de la Torre se pregunta si es preciso invocar la continuidad histórica de Occidente para recuperar Paideia o Bildung y para darle sentido a nuestra educación; concluye que son eventos y contextos distintos. Sin embargo, en 
su reflexión, invita a enfrentar el pragmatismo y la competitividad de la educación predominante con los modelos de la Paideia y la Bildung en tanto estas ofrecen: "a) una mayor preocupación por lo humano y b) un enfoque más integral y formativo de los contenidos, estrategias y finalidades de la educación" (2009, p.2).

El discurso pedagógico alemán regresa a Grecia y Roma en busca de la esencia de un sujeto heroico que aspira a la trascendencia singular en un colectivo humano en un marco de religiosidad moderno. De Goethe hasta Jaeger se anima un concepto de pedagogía sobre los sedimentos de un héroe que anuncia y enuncia: Wilhelm Meister (1789) propone la formación del sujeto lector de la modernidad que huye de la guerra en estratos temporales de larga y corta duración que desembocan en Paideia (1942).

Se llama a engaño cuando se pretende comprender la humanidad despojándola de ese sabor a muerte que ha aprendido de la guerra a lo largo de la historia. Quizás esté por escribirse sobre los aprendizajes o las pedagogías de la guerra; si alguien lo hace, no podrá dejar por fuera el componente bélico ¿Cuántas lecciones, aún las más amargas, ha dejado en nuestro legado la indecible y permanente guerra?

Goethe, Kant, Humboldt, Herbart y Jaeger descubren un hombre con su estructura corporal y espiritual capaz de crear condiciones para el mantenimiento y transmisión de sus concepciones y concebir organizaciones físicas y espirituales cuyo conjunto conforma un concepto de educación y pedagogía que activa la fuerza vital y creadora que impulsa a toda especie viva al mantenimiento y propagación de su tipo con el fin de formar sociedad. Esta adquiere el más alto grado, mediante el esfuerzo consciente del conocimiento y de la voluntad dirigida a un fin. La pedagogía, en sus nexos con la educación, son más que la conjugación de normas con las que se pretende formar al hombre, son el hombre mismo.

\section{CODA}

La Bildung alemana guarda relación con la Paideia griega en cuanto a su envergadura científica, política y humana. En esencia, compromete la cultura y es la síntesis de la formación personal singular y colectiva o social del pensamiento ilustrado. Su emergencia se da con el empoderamiento de las ciencias empíricas y de la difusión intensiva de la lectura y la escritura lo que trazó la ruta de la pedagogía como la ciencia de la educación que solo puede ser leída como un discurso escrito que sitúa al hombre en el epicentro de la Modernidad y como un sujeto que puede ser observado, analizado, diseccionado y gobernado desde disciplinas que permiten contabilizar, medir, calcular y predecir acontecimientos y, además, gobernar y moralizar a las personas.

Si bien la Ilustración se aferró a la razón y al método experimental para comprender y ordenar el mundo y para establecer metas socioeconómicas y políticas precisas, Bildung abrió un abanico de posibilidades mas humanas: "Bildung del entendimiento sin Bildung del corazón y del gusto es simplemente Ilustración" (Koselleck, pp.58-59).

Koselleck subraya que el concepto Bildung: ${ }^{13}$ a) no es un concepto preestablecido, es una suerte de estado procesual que se modifica de modo constante y activo: "Bildung es tanto el proceso de producción como el resultado de lo producido; b) Bildung no se refiere a: un conocimiento determinado, una ciencia, una posición política o principio social, una

13 De modo reciente, el colombiano Carlos Ernesto Noguera recupera a Wolfgang Klafki (1987) para abordar el significado de Bildung desde cuatro perspectivas. Primera, la Bildung: "[...] se expresa mediante los conceptos de autodeterminación, libertad, emancipación, autonomía, mayoría de edad, razón, auto-actividad y, en ese sentido, significaría capacitación para la autodeterminación racional en donde la auto-actividad es la forma central de realización del proceso formativo" (Noguera, 2010, p.6). Segunda: "[...] puede ser entendida como el desenvolvimiento del sujeto en el mundo objetivo universal [...] el concepto de Bildung privilegia las producciones humanas, las ganancias civilizatorias en la satisfacción de las necesidades, el conocimiento sobre la naturaleza y sobre el mundo humano, las acciones políticas, los sistemas de normas y acciones éticas, las formas de vida social, los productos estéticos, etc." (p.6). Tercera: "[...] implica una relación dialéctica entre la individualidad y la colectividad, es decir, la formación de la individualidad es la manera particular como se concretiza, en cada caso, la objetividad general (mundo, cultura) y tal concretización solo es posible mediante la apropiación y discusión crítica de la objetividad general" (p.6). Y cuarta, según las teorías clásicas existirían tres dimensiones de la actividad humana que deben ser objetivo de la Bildung: la dimensión moral, la cognitiva y la estética (pp.6-7). 
confesión o vinculación religiosa, una opción ideológica o preferencia filosófica o una tendencia estética (artístico o literaria) particular (Koselleck, 2012, pp.54-55).

Bildung, Bildungsroman y Paideia en son tres conceptos en los cuales se escribe la utopía alemana ilustrada y racional en dos momentos clave: en el fragor revolucionario industrial y social del siglo XVIII y en la modernidad bélica del siglo XX, estos emergen de una sociedad urgida de héroes, que escribe y lee su epopeya pedagógica a la par del método experimental en una perspectiva de religiosidad estética, política y cultural y sobre las cenizas grecolatinas.

El concepto alemán de pedagogía, vista como Paidos y Bildung, trasciende la reiterada instrucción del niño o la formación profesional y la sitúan como una ciencia del cuerpo y del espíritu propias de una educación redentorista que ofreció su perspectiva salvífica al pueblo alemán en sus momentos de crisis.

\section{RECONOCIMIENTOS}

Este artículo de reflexión es producto del proyecto titulado El concepto de pedagogía de la lectura en la modernidad. Este fue institucionalizado por el Centro de Investigaciones de la Universidad Distrital Francisco José de Caldas (UDFJC) en diciembre de 2013 luego del aval del Grupo de Investigación, Lenguaje cultura e Identidad de la misma Universidad..

\section{REFERENCIAS}

Abellán, J. (2003). Estado y nación en Guillermo von Humboldt. Revista Internacional de los Estudios Vascos, 48(1), 329-344.

Bajtin, M. (1999). Estética de la creación verbal (Trad. Tatiana Bubnova). Décima edición. México: Siglo XXI.

Bisquerra, R. (1996). Orígenes y desarrollo de la orientación psicopedagógica. Madrid: Narcea.

Cavallo, G. y Chartier, R. (Coord.). (1998). Historia de la lectura en el mundo occidental. Segunda edición. Madrid: Santillana, Taurus.
Certeau, M. (2000). La invención de lo cotidiano. Volumen 1: Artes de hacer. México: Universidad Iberoamericana, Biblioteca Francisco Javier Clavijero.

De la Torre, M. (2009). Ideología y representaciones sociales de la buena educación. X Congreso Nacional de Investigación Educativa, Veracruz.

Escudero, V. (2010). Reflexiones sobre el sujeto en el primer Bildungsroman. Departamento de Filología Románica, Universitat de Barcelona Curso 2007/2008. Recuperado de http://diposit.ub.edu/ dspace/bitstream/2445/12126/1/Reflexiones $\% 20$ sobre $\% 20$ el $\% 20$ sujeto $\% 20$ en $\% 20$ el $\% 20$ primer\%20Bildungsroman $\% 20 \% 28 \mathrm{~V} \% \mathrm{C} 3 \%$ ADctor\%20Escudero\%29.pdf

Fabre, M. (2011). Experiencia y formación: la Bildung (Trad. Alejandro Rendón Valencia). Educación y Pedagogía, 23(59), 215-225.

Foucault, M. (2007). Seguridad, territorio, población. México: Fondo de Cultura Económica.

Goethe, W. (2008). Los años de aprendizaje de Wilhelm Meister (Trad. Miguel Salmerón). Madrid: Cátedra.

Herbart, J. F., (1935). Bosquejo para un curso de pedagogía. Madrid: Espasa Calpe.

Herbart, J. F. (1941). Pedagogía general. Derivada del fin de la educación (Trad. Lorenzo Luzuriaga). Madrid: Humanitas.

Hernández, A. (2004). Introducción a la crítica de la razón pura. San Vicente: Club Universitario.

Humboldt, W. von (2009). Los límites de la acción del Estado. Madrid: Tecnos.

Jaeger, W. (1992). Paideia: Los ideales de la cultura griega. México: Fondo de Cultura Económica.

Julia, D. (1998). Lecturas y contrarreforma. En G. Cavallo y R. Chartier. Historia de la lectura en el mundo occidental (299-332). Madrid: Santillana, Taurus.

Kant, I. (1999). Respuesta a la pregunta: ¿Qué es ilustración? En J. Alcoriza y A. Lastra (Ed.). En defensa de la llustración (63-71). Barcelona: Alba.

Kant, M. (2003). Sobre Pedagogía. En M. Kant, J. E. Pestalozzi y J. W. Goethe. Sobre educación (Composición y traducción de Lorenzo Luzurriaga). Biblioteca Virtual Universal. Recuperado de http:// www.biblioteca.org.ar/libros/89419.pdf 
Kant, I. (2004). Tratado de pedagogía. Cali: Universidad del Valle.

Klafki, W. (1990). La importancia de las teorías clásicas de la educación para una concepción de la educación general hoy. Revista de Educación, 291, 105,121.

Koselleck, R. (1993). Futuro pasado: para una semántica de los tiempos históricos (Trad. Norberto Smilg). Paidós: Barcelona.

Koselleck, R. (2001). Los estratos del tiempo: estudios sobre historia (Trad. José Elías Palti). Barcelona: Paidós.

Koselleck, R. (2007). Crítica y crisis. Estudio sobre la patogénesis del mundo burgués (Trad. Rafael de la Vega, Jorge Pérez de Tudela). Julio A. Pardos (Ed.). Madrid: Trotta.

Koselleck, R. (2012). Sobre la estructura antropológica y semántica de Bildung. En R. Koselleck. Historia de conceptos. Estudios sobre semántica y pragmática del lenguaje político y social (49-93). Madrid: Trotta.

Koselleck, R. y Gadamer, H.-G. (1997). Historia y hermenéutica. Barcelona: Paidós.

Lasso, J. (1962). En la muerte de Werner Jager. Estudios Clásicos, 37, 30-47. Recuperado de http://interclassica.um.es/var/plain/storage/original/application/e6cd44840582888e2f194bbf79aec508.pdf

Luzuriaga, L. (1946). Historia de la educación pública. Buenos Aires: Losada.

Martínez, A. (2011). Universidad y formación en tiempos de encrucijada. Conferencia preparada para el foro El sentido formativo de la universidad en el mundo contemporáneo. Cali: Universidad del Valle, 24 de junio.

Mayer, F. (1967). Historia del pensamiento pedagógico. Buenos Aires: Kapelusz.
Montealegre, A. (2007). Formación del método experimental y su utilización en pedagogía. Bogotá: Universidad de San Buenaventura.

Noguera, C. E. (2010). Aproximación conceptual a la constitución de las tradiciones pedagógicas modernas. Lección inaugural del Doctorado Interinstitucional en Educación. Bogotá: Universidad Pedagógica Nacional.

Quiceno, H. (2003). Michel Foucault, ipedagogo? Educación y Pedagogía, 15(37), 201-216.

Rojas, O. (2010). Filosofía de la educación de los griegos a la tardomodernidad. Medellín: Universidad de Antioquia.

Rousseau, E. (2010). Emilio o la educación. México: Porrúa.

Runge, A. y Garcés G. (2011). Educabilidad, formación y antropología pedagógica: repensar la educabilidad a la luz de la tradición pedagógica alemana. Revista Científica Guillermo de Ockham, 9(2), 13-25.

Runge, A. K. (2009). La ética de Johann Friedrich Herbart como estética en sentido formativo o de cómo abrirle un espacio de posibilidad a la educación. Universidad de Antioquia, Facultad de Educación, 21(55), 55-74.

Vilonou, C. (2002). Formación, cultura y hermenéutica: de Hegel a Gadamer. Revista de Educación, 328, 205-223.

Wittmann, R. (1998). ¿Hubo una revolución de la lectura en el mundo occidental? En G. Cavallo y R. Chartier. Historia de la lectura en el mundo occidental (435472). Madrid: Santillana, Taurus.

Zuluaga, O. (2003). Pedagogía y epistemología. Bogotá: Cooperativa Editorial Magisterio. 